\title{
Jellyfish swarms and degree of exposure and vulnerabil- ity of recreational and tourist activities on beaches. Methodological approach to their assessment in the La- gos-Ferrara sector (Málaga, Spain)
}

\author{
Francisco José Cantarero Prados ${ }^{10000-0002-4811-8724]}$ and Alejandro Miguel Moreno Por- \\ tillo 2 [0000-0002-6235-8345]

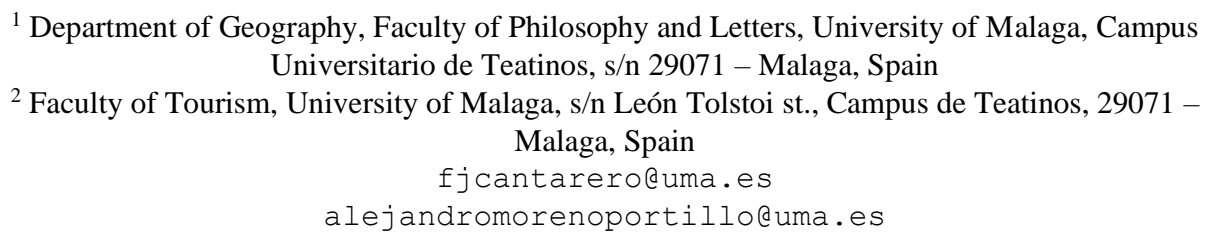

\begin{abstract}
An important part of the economy of the municipalities on the southern Spanish coast revolves around tourist activity, whose main attraction is the sun and beach. Events such as the arrival of swarms of jellyfish on their beaches have generated a certain amount of fear in the tourism sector. This work presents a methodological essay to evaluate the possible impact of this phenomenon on the use of the beach and the tourist economic activity linked to it. The chosen study area is the stretch of coast between the beaches of "Lagos" and "Ferrara" (eastern coast of the province of Málaga). It is developed from a risk management perspective, addressing exposure and vulnerability factors. The sources are mainly surveys. The results show that in the short term there are no clear consequences, but there are in the long term.
\end{abstract}

Keywords: Vulnerability, beaches, jellyfish, risk, tourism, Málaga, Spain.

\section{Introduction}

Swarms of jellyfish (mainly Pelagia noctiluca) could represent a threat to tourist activity on the Costa del Sol (Spain). This fear has been aroused by the intense arrival of this species on its beaches in the summer of 2018. Jelly distribution and proliferation has been studied for a long time from various scientific approaches. Condon et al. [9] states that recurrent jellyfish swarms are a consequence of global oscillations. The rates of colony emergence have been compared to the current process of climate change [4], but it cannot be said that there is an unequivocal relationship between increased jellyfish swarms emergence rates and global warming $[16,20]$. This phenomenon has also been studied in the Mediterranean Sea with regard to its biological proliferation [5, 7, 22, among others] and the relationship between the appearance of swarms and climate dynamics [2]. However, despite the progress made, there is insufficient knowledge to accurately predict the future evolution of the rates of jellyfish 
appearance in the medium and long term, at least in the area of the Alborán Sea (southern Iberian Peninsula). The massive arrival of jellyfish in the summer of 2018 logically generated concern. It was so extraordinary that it has sown doubts about whether it was just an outlayer or a warning of a change of cycle. As this issue has not been fully calibrated, despite the progress made, uncertainty about the evolution of the rate of appearance of jellyfish is a concern on the coast of southern Spain, mainly because tourism is the main economic activity. In light of this risk, it is necessary to manage it territorially by estimating the consequences for society in scenarios of aggravation of the threat to human beings. This work has this objective: to analyze the exposure and vulnerability of human use of beaches in a sector of the southern coast of Spain. For this purpose, the analysis is structured through risk analysis from the perspective of Disaster Risk Management [3]. The analysis of exposure and vulnerability is approached, which, together with hazard, is one of the three constitutive elements of the study of natural risk from a territorial perspective [18]. If jellyfish can be considered a threat, the risk to humans is given by the probability of damage (physical, such as stings, and in the form of a drop in economic activity, in case of a decrease in economic activity) or loss (mainly due to the consequences of a hypothetical drop in visits to beaches that are affected by jellyfish). Progress has already been made with regard to the impact of jellyfish stings on human health $[6,12,14]$, also at the socio-economic level in certain sectors such as fishing [17, 23] and in tourism [11, 13, 21]. The interest of this study is to consider all the possible aspects in which their appearance on the coasts can imply an effect on the human activity on the beaches, both recreational and tourist. That is to say, not only the economic activity generated by tourism is taken into account, but also the recreational use that both the local population and visitors make of the beaches. Vulnerability analysis applied to territorial risk management is widespread at both the academic and institutional levels [19] and it has been already applied to coastal management $[8,10,25]$. In the specific case of jellyfish, it is assumed that the consequences of their appearance on beaches may vary depending on the activity (recreational or economic) and the time scale in which the analysis is carried out. For example, the arrival of a swarm on a particular day could bring more economic benefits than on a day without jellyfish to certain activities such as restaurants, nearby swimming pools, pedal boats, pharmacies, etc. However, in the long term (two or three summers seen in a scenario with repeated visits of jellyfish in all of them) could cause the activity to decline due to a general decrease in tourism. Therefore, this paper attempts to address the effects that jellyfish may have by focusing on various temporal and spatial scales. The selected study area is a sector of the coast of southern Spain located in the municipalities of Velez-Malaga and Torrox. It consists of four beaches: Lagos, El Morche, El Cenicero and Ferrara, arranged from west to east (figure 1). They are all listed in the Guía de Playas del el Ministerio de Agricultura y Pesca, Alimentación y Medio Ambiente [15]. 


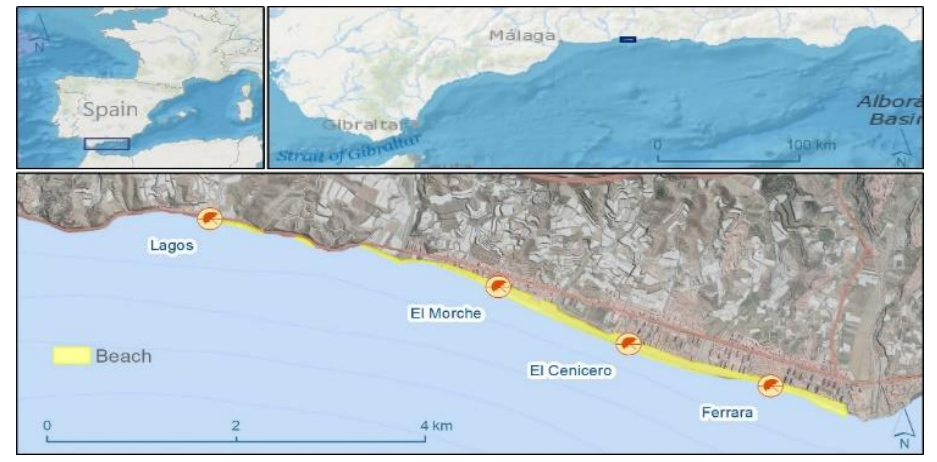

Fig. 1. Location map of the study area: Sector of the coast between the beaches of Lagos and Ferrara (Málaga province, Spain). Prepared by the authors based on the World Ocean Reference (Esri, 2020), DERA (IECA, 2019), Plan Nacional de Ortofotografía Aérea (2016) and MAPAMA [15] | Terrestrial Reference System: World Geodetic System 1984.

\section{Methodology}

The proposed methodology analyses the vulnerability of human use of beaches and their areas of influence. It is conducted using various temporal and spatial scales as proposed by Cantarero et al. [8].

Two scales are considered in the spatial dimension of the vulnerability analysis:

- Detailed (beach): the one with the highest approach or resolution, the study area is limited to the beach and the seafront.

-Area of influence: Covers an area that goes beyond the beach itself, reaching nearby areas where economic activity is largely related to tourist activity on the beach.

At a temporary level, 2 scales are established:

- Short term: addressing the possible immediate impact of the arrival of a swarm of jellyfish, that is, what happens if jellyfish swarm visits the beach on a particular day.

- Long term: to consider the consequences of a possible scenario of an increase in the frequency of blooms of jellyfish in future seasons.

The sources for working on these 4 spatial-temporal contexts are surveys and interviews carried out through field work both on the beach and in its area of influence. Depending on this context, one, the other or both will be used.

\subsection{Analysis of possible short-term consequences}

This first unit focuses on the possible immediate consequences of the arrival of a swarm of jellyfish on a particular day at the beach. This analysis is divided into two sections: the repercussions on the beach (at the use level and on economic activity 
linked to tourism) and on the area of influence (specifically on economic activity linked to tourism).

Detailed analysis (on the beach) in the short term (in the immediacy of time). The starting point is the evaluation of the exposure factor (of the users and the existing economic tourism activities on the beach) and then the vulnerability of both the users and the economic activities themselves. This phase of the analysis is divided into 2 factors, which in turn are broken down into 5 sub-factors measured through a total of 10 indicators. Finally, as the ending part of this section, the consequences on economic activity are also estimated, that is, the degree of affectation (positive or negative) experienced by the establishments if on a specific day a swarm of jellyfish reaches on the beach.

Table 1. Analytical structure used in the methodology to estimate the exposure and vulnerability of recreational and tourist use of beaches in the detailed analysis -on the beach itself- in the short term -in the temporal immediacy-)

\begin{tabular}{|c|c|c|c|c|}
\hline FACTOR & \multirow{2}{*}{\multicolumn{2}{|c|}{$\frac{\text { SUB-FACTOR }}{\text { Gross exposure }}$}} & \multicolumn{2}{|r|}{ INDICATOR } \\
\hline \multirow[b]{3}{*}{ Exposure } & & & 1 & Type/Provenance of users \\
\hline & \multirow{2}{*}{\multicolumn{2}{|c|}{ Net exposure }} & 2 & $\begin{array}{l}\text { Main motivation for decid- } \\
\text { ing to go to the beach }\end{array}$ \\
\hline & & & 3 & $\begin{array}{c}\text { Personal preference to take a } \\
\text { bath in the sea on } 100 \% \text { of the } \\
\text { occasions when going to the } \\
\text { beach }\end{array}$ \\
\hline \multirow{7}{*}{$\begin{array}{l}\text { Vulnerabil- } \\
\text { ity }\end{array}$} & \multirow{7}{*}{$\begin{array}{c}\text { User } \\
\text { vulnerability }\end{array}$} & \multirow{3}{*}{$\begin{array}{l}\text { Level of discom- } \\
\text { fort or dissatisfac- } \\
\text { tion }\end{array}$} & 4 & $\begin{array}{l}\text { Assessment of the experi- } \\
\text { ence in the face of the arrival of } \\
\text { jellyfish or other impediments } \\
\text { to bathing in the sea }\end{array}$ \\
\hline & & & 5 & $\begin{array}{l}\text { Willingness to stay on the } \\
\text { beach in case of the arrival of a } \\
\text { jellyfish swarm }\end{array}$ \\
\hline & & & 6 & $\begin{array}{l}\text { Comparison of jellyfish dis- } \\
\text { comfort with other unpleasant } \\
\text { experiences at the beach }\end{array}$ \\
\hline & & \multirow{3}{*}{$\begin{array}{l}\text { Protective } \\
\text { measures against } \\
\text { Jellyfishes (Preven- } \\
\text { tive information, } \\
\text { mitigation features, } \\
\text { physical protection) }\end{array}$} & 7 & $\begin{array}{c}\text { Preventive information: } \\
\text { Knowledge of the app "Infome- } \\
\text { dusa" [1] }\end{array}$ \\
\hline & & & 8 & $\begin{array}{l}\text { Physical protection: Jelly- } \\
\text { fish protection equipment }\end{array}$ \\
\hline & & & 9 & $\begin{array}{c}\text { Mitigation features: } \\
\text { Knowledge of how to act in } \\
\text { case of a sting }\end{array}$ \\
\hline & & $\begin{array}{l}\text { Alternatives to } \\
\text { bathing }\end{array}$ & 10 & $\begin{array}{l}\text { Alternatives to bathing in } \\
\text { case of impossibility due to the } \\
\text { presence of jellyfishes }\end{array}$ \\
\hline
\end{tabular}




\begin{tabular}{|c|c|}
\hline $\begin{array}{c}\text { Vulnerability of economic ac- } \\
\text { tivity related to tourism }\end{array}$ & $\begin{array}{c}\text { Qualitative estimation through in- } \\
\text { terviews with businesses in the area of } \\
\text { study }\end{array}$ \\
\hline
\end{tabular}

The following sections are dealt with:

Gross exposure. It is based on a double inventory: a count of the users who go to the beach and another one of economic activities. In the first one, users are classified according to their typology (based on their origin): locals, holidaymakers (people from outside the municipality or region of study who spend in it their summer holidays), occasional tourists (visitors who change their destination regularly and therefore will probably choose a new destination in the coming years).

In economic activities level, it is took into account both those located on the sand itself and those located on the built seafront are taken into account.

Net exposure. This name is intended to define the number of users who may indeed be affected by the presence of jellyfish. These are the ones that come to the beach with the intention of taking a bath. Those who come with other intentions are not counted. Two criteria are proposed to estimate this factor: a) main motivation for deciding to go to the beach, b) personal preference to take a bath in the sea on $100 \%$ of the occasions when going to the beach.

Vulnerability. As shows table 2, this factor is divided in 7 indicators for user's vulnerability and addressed by qualitative estimation in the case of the vulnerability of economic activity related to tourism assessment.

Analysis in the area of influence. Research in this area is less exhaustive than in the previous one. It focuses on economic aspects and is also implemented with field work, applying semi-structured interviews to workers in tourism-related activities. The aim is to determine whether on a day when jellyfish are present, any difference is observed in the daily activity of the business. Hotels, bars and restaurants, pharmacies and private parking lots are included in this task.

\subsection{Analysis of long-term consequences}

Estimation of possible consequences on the beach and area of influence in the long term. A survey has been used in order to evaluate the long-term social and economic effect of jellyfishes on the beach recreational uses and touristic activity. They basically question the interviewees on their preference or behaviour in the case of the scenario already proposed in this hypothesis: that a recurrent arrival of jelly-fish swarms would be experienced on their beach in the present and successive seasons.

Due to the different circumstances or motivations for which the beach that is the object of this study is visited; it has been decided to separate all of these into local population, holidaymakers and 


\section{Results}

Two days were required to collect data: 25 to 26 June 2019 between 12:00 - 14:00 h and from 15:00 - 18:00 h. It was estimated that there were about 500 people on the beaches of the sector, so it was necessary to make 207 surveys to obtain results with a confidence level of $95 \%$.

\subsection{Short term analysis}

Gross exposure. The number of visitors to the beaches on the stretch of coast covered by this study is increasing towards its eastern end. In approximate relative values, most users are concentrated on the beach of Ferrara, $41 \%$, followed by the beaches of El Cenicero, El Morche and Lagos with 30\%, 25\% and $4 \%$ respectively.

In the same way, the density of establishments with a tourist function is also increasing towards the east. Figure 2 shows their distribution.

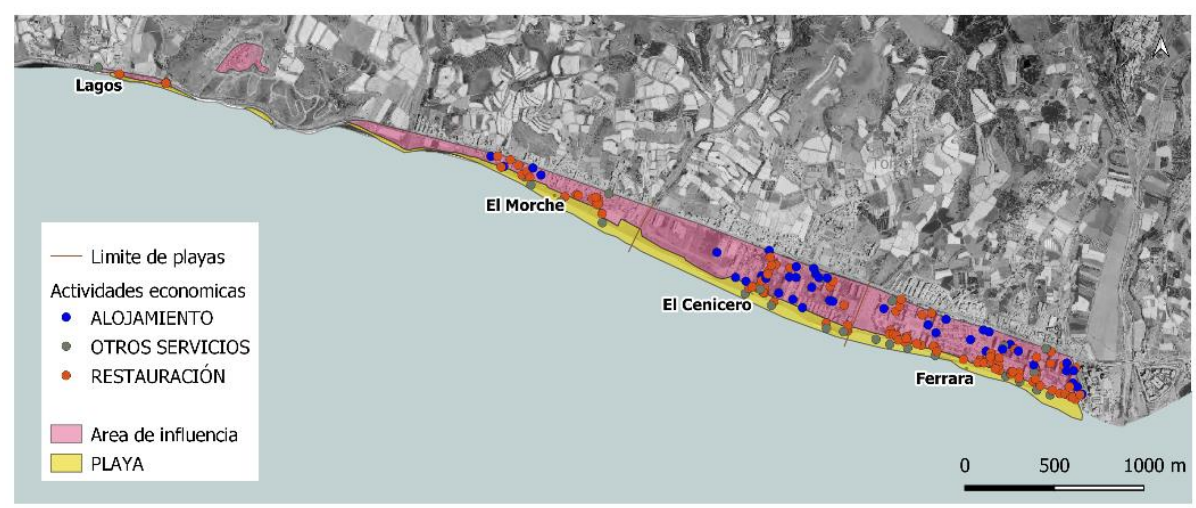

Fig. 2. Distribution of economic activities with a tourist function in the Lagos-Ferrara beach sector. Source: Own elaboration based on IECA (2020).

More than half of the users are local, reaching 63\%. The rest is occupied by holidaymakers with $32 \%$ and casual visitors with only $5 \%$. Most of them own a house in the area $(83 \%$ of the users interviewed).

\section{Net exposure}

Reason for deciding to go to the beach. A little more than half of the users go to the beach with the main motivation of taking a bath $(55 \%)$. The rest of the users $(45 \%)$ come mainly for aesthetics (getting a tan), to practice sport and for entertainment, representing $26 \%, 16 \%$ and $3 \%$ respectively. 
Personal preference to take a bath in the sea on $100 \%$ of the occasions when going to the beach. Most of the visitors interviewed (55\%) stated that they always take a bath in the sea, a proportion of $35 \%$ do so almost always, $7 \%$ only if the water temperature pleases them (if it is not too cold) and the remaining 3\% never take a bath in the sea.

\section{Users vulnerability}

Assessment of the experience in the face of the arrival of jellyfish or other impediments to bathing in the sea. Most of the users interviewed consider that the arrival of a swarm of jellyfish implies that their experience on the beach is bad (40\%) or very bad $(50 \%)$, the remaining $10 \%$ observe this circumstance indifferently.

Willingness to stay on the beach in case of the arrival of a jellyfish swarm. Despite the bad experience declared in the previous indicator, if on a given day a swarm of jellyfish appears on the beach, most visitors declare that they would remain there $(81 \%)$. The remaining $19 \%$ would leave the beach.

Comparison of jellyfish discomfort with other unpleasant experiences at the beach. When asked about a series of frequent problems, respondents rated dirt and jellyfish as the worst. On the other hand, the low water temperature, the situations of high concurrence of the beach or adverse meteorological situations such as the foehn effect (in Malaga it is known as the local term "terral") are not a clear impediment for the users of the beaches in this area of study.

Knowledge of the app "Infomedusa" [1]. Only 10\% have installed some kind of application with information on the evolution of jellyfish in the coast.

Use of jellyfish protection.. Only $7 \%$ of the users interviewed use jellyfish protection.

Knowledge of how to act in case of a sting. Although $58 \%$ know some procedure to follow in case of a sting, some interviewees indicate remedies such as vinegar, urine that are not advised by medical protocols. Some others answered that their solution would be to go to the lifeguard for help.

Alternatives to bathing in case of impossibility due to the presence of jellyfishes.. The alternative that users contemplate in case of being impossible to take a bath is to use swimming pools, either their own $(22 \%)$ or those that are accessible for various reasons $(6 \%)$. A quarter would take the bother of moving to another beach while $47 \%$, who do not have access to swimming pools, indicate that they would have to stay and be content with the situation generated by the jellyfish. 
Vulnerability of economic activity related to tourism. About $22 \%$ of the restaurants surveyed indicate that they have detected a certain increase in their activity during episodes of jellyfish arrival on the beach. The explanation given by the restaurant businesses interviewed is that users choose to go to their establishments when jellyfish are present. However, a majority, $78 \%$ of the remaining businesses do not indicate any change. The only spa in the area they indicate that the turnover has increased at times of high influx of jellyfish on the beaches. One pharmacy noticed more sales than normal due to demand from users who needed sting remedies.

The remaining businesses are two car rentals and a spa. In. For its part, rent a car, logically, have not noticed any change

\subsection{Long-term analysis}

Field surveys have also been used to find out if users would continue to choose the study area if their beaches started to experience a recurrent arrival of jellyfish in the coming seasons. $83 \%$ of local users would not change beaches. As for the tourists, moved to the area only during the holiday period, $44 \%$ would remain loyal to the beaches in the area, $39 \%$ would change beaches and $17 \%$ were undecided. On the other hand, users or occasional tourists, $17 \%$ would not change beaches, $64 \%$ would change beaches and $20 \%$ do not know if they would change.

\section{Conclusions}

The Lagos-Ferrara sector indicates a considerable vulnerability of the beach user to the phenomenon of jellyfish swarms. Although in the short term there are no negative impacts on economic activities with a tourist function (if any positive) in the long term some current visitors indicate that they could change area if the arrival of jellyfish were to continue frequently in the future.

Users show some concern in the interviews in the analysis of short-term consequences, however, the answers given in the section on prevention and protection in the event of the arrival of jellyfish (knowledge of health protocols for action, having the Infomedusa application [1] installed, etc.) indicate that there is currently no strong interest in how to act or in having predictive information about the appearance of jellyfish on the beaches they visit. In fact, a large number of these users indicate that they would tolerate the impossibility of bathing while remaining on the beach without being able to refresh themselves.

The lack of knowledge or interest in having preventive information or action against consequences (stings) coincides with the results of Vandendriessche et al. [24] which indicate that most respondents on the Belgian coast had little knowledge about various aspects related to jellyfish, such as their causes, the type of threat they represent and the solutions that can be applied.

The fact of having a dwelling in the area seems to be a determining factor in the way of acting. In the analysis of long-term consequences, a large majority of local users would not change beaches $(83 \%)$. In the same vein, a large number of users who 
spend their holidays in the area (44\%) would do so even if the arrival of jellyfish on the beaches were to become more frequent. Having a property in the area (a secondary residence in this case), seems to be the main reason for not moving from its beaches, besides the climate or circumstances such as having relatives residing in the area. This may be due to what Kontogianni and Emmanouilides [13] call "sense of place" in their results for the Gulf of Lion, i.e. a kind of "rooting". This does not mean that the locals or holidaymakers enjoy the jellyfish episodes at all, but that they prefer to endure the bad experience by staying on the beach. This circumstance indicates, in a way, a kind of resilient behaviour of most of the users of these beaches. However, there is a lower proportion of holidaymakers and a high proportion of occasional tourists than if they declared that they would leave these beaches if the phenomenon were repeatedly observed in the future. This could probably mean economic losses. In this regard, it is necessary to continue to quantify them. Some studies have already begun in the tourism sector [17]. It would be worthwhile directing further researches to the role of the media. There are some works that have used news as a way of approaching the phenomenon of jellyfish $[9,21]$. The challenge that remains is to assess the longterm effect of bad news about jellyfish on the decision-making of potential tourists.

\section{References}

1. Aula del Mar y Desarrollos Digitales Malva2 (2013). Infomedusa. Mobile phone application. Available in https://play.google.com/store/apps/details?id=es.infomedusa\&hl=es

2. Bellido, J., Báez, J., Souviron-Priego, L., Ferri-Yañez, F., Salas, C., López, J., \& Real, R. (2020). Atmospheric indices allow anticipating the incidence of jellyfish coastal swarms. Mediterranean Marine Science, 0, 289-297. doi:https://doi.org/10.12681/mms.20983.

3. Birkmann, J.; Kienberger, S.; Alexander, D. (2014). Assessment of Vulnerability to Natural Hazards: A European Perspective. Ed. Elsevier. ISBN 0124105483, 9780124105485.

4. Bjelland, H. V., Liu, Y., Knutsen, Ø., Eisenhauer, L., Mork, J., Bailey, J. \& Tiller, R. G. (2016). Coming Soon to a Fjord Near You: Future Jellyfish Scenarios in a Changing Climate. Coastal Management, 45(1), 1-23, https://doi.org/10.1080/08920753.2017.1237239

5. Boero, F., (2013). Review of Jellyfish Blooms in the Mediterranean and Black Sea. Studies and Reviews. General Fisheries Commission for the Mediterranean, 93.

6. Bordehore, C., Alonso, C., Sánchez-Fernández, L., Canepa, A., Acevedo, M., Nogué, S. \& Fuentes, V. L. (2016). Lifeguard assistance at Spanish Mediterranean beaches: Jellyfish prevail and proposals for improving risk management. Ocean \& Coastal Management, $131,45-52$.

7. Canepa, A., Fuentes, V., Sabatés, A., Piraino, S., \& Boero, F. (2014). Pelagia noctiluca in the Mediterranean Sea. En Jellyfish Blooms (págs. 237-266). Netherlands, Dordrecht: Springer.

8. Cantarero Prados, F.J.; Reyes Corredera, S.; Plaza Santiago, R.; Perles Roselló, M.J. (2020). Contribución al análisis del riesgo de afectación por medusas en el litoral malagueño. Sector Torre del Mar - Caleta de Vélez. En Mora Aliseda,J; Garrido Velarde, J. y Castro Serrano, J. (Coord.). Espacios y sociedades en transformación. Ed. Thomson Reuters - Aranzadi. Pp 61 a 74. ISBN 9788413466958.

9. Condon, R.H., Duarte C.M, Pittd K.A., Robinson K.L., Lucas C.H., Sutherland K.R., Mianzan H.W., Bogeberg M., Purcell J.E., Decker M.B., Uyek S., Madin L.P., Brodeur R.D., Haddock S. H., Malej A., Parry G.D., Eriksen R., Quiñones J., Acha M., Harvey M., 
Arthur J.M. y Graham W.M. (2013). Recurrent jellyfish blooms are a consequence of global oscillations, Proc. Natl. Acad. Sci. 110: 1000-1005. Proceedings of the National Academy of Sciences of the United States of America 110: 1000-100.

10. Garmendia Pedraja, C.; Rasilla Álvarez, D.F.; Rivas Mantecón, V. (2017) Distribución espacial de los daños producidos por los temporales del invierno 2014 en la costa norte de España: peligrosidad, vulnerabilidad y exposición. Estudios Geográficos, Vol. LXXVIII, 282, pp. 71-104, Enero-junio 2017, ISSN: 0014-1496, eISSN: 1988-8546.

11. Ghermandi, A., Galil, B., Gowdy, J., Nunes, P. a. L.D., (2015). Jellyfish outbreak impacts on recreation in the Mediterranean Sea: welfare estimates from a socioeconomic pilot survey in Israel. Ecosyst. Serv. 11, 140e147. http://dx.doi.org/ 10.1016/j.ecoser.2014.12.004.

12. Killi, N. \& Mariottini, G. L.(2018). Cnidarian Jellyfish: Ecological Aspects, Nematocyst Isolation, and Treatment Methods of Sting. In KlocJacek, M. and Kubiak, Z. (coord.) Marine Organisms as Model Systems in Biology and Medicine, pp 477-513.

13. Kontogianni, A. D., \& Emmanouilides, C. J. (2014). The cost of a gelatinous future and loss of critical habitats in the Mediterranean. ICES Journal of Marine Science, 71(4), 853866.

14. Li, L., McGee RG, Isbister G,Webster A.C. (2013) Interventions for the symptoms and signs resulting from jellyfish stings. Cochrane Database of Systematic Reviews 2013, Issue 12. Art. No.: CD009688. DOI: 10.1002/14651858.CD009688.pub2

15. MAPAMA (2019). Guía de Playas. Url: https://www.miteco.gob.es/.

16. Møller L.F., Canon J.M., Tiselius P. (2010) Bioenergetics and growth in the ctenophore Pleurobrachia pileus. In: Purcell J.E., Angel D.L. (eds) Jellyfish Blooms: New Problems and Solutions. Developments in Hydrobiology 212, vol 212. Springer, Dordrecht.

17. Nastav, B., Malej, M., Malej, A., 2013. Is it possible to determine the economic impact of jellyfish outbreaks on fisheries? a case study e Slovenia. Mediterr. Mar. Sci. 14, 214e223.

18. Olcina Cantos, J (2002). "Conceptos de aplicación en el Análisis de Riesgos". In Ayala Carcedo, F. J. y Olcina Cantos, J. (eds.): "Riesgos naturales". Ariel, Barcelona,pp 59-73

19. Perles Roselló, M.J. (2010). "Apuntes para la evaluación de la vulnerabilidad social frente al riesgo de inundación". Baetica. 32, 2010, 67-87. ISSN: 0212-5099.

20. Purcell, J. E., Uye, S. I. \& Lo, W. T. (2007). Anthropogenic causes of jellyfish blooms and their direct consequences for humans: A review. Marine Ecology Progress Series, 350, 153-174. https://doi.org/10.3354/meps07093

21. Rubio Gómez, A.; Gutierrez Hernández, O. (2020). Impacto de las medusas y otros organismos gelatinosos en el litoral andaluz. Implicaciones para el turismo de sol y playa. Estudios Geográficos, 81 (288), enero-junio 2020, e038 ISSN: 0014-1496 | eISSN: 19888546. https://doi.org/10.3989/estgeogr.202053.033

22. Sabatés A., Pagès F., Atienza D., Fuentes V., Purcell J.E., Gili JM. (2010) Planktonic cnidarian distribution and feeding of Pelagia noctiluca in the NW Mediterranean Sea. In: Purcell J.E., Angel D.L. (eds) Jellyfish Blooms: New Problems and Solutions. Developments in Hydrobiology 212, vol 212. Springer, Dordrecht. https://doi.org/10.1007

23. Tomlinson, B., Maynou, F., Sabatés, A., Fuentes, V., Canepa, A. \& Sastre, S. (2018). Systems approach modelling of the interactive effects of fisheries, jellyfish and tourism in the Catalan coast. Estuarine, Coastal and Shelf Science, 201, 198-207.

24. Vandendriessche, S., Vansteenbrugge, L., Derweduwen, J., Maelfait, H., \& Hostens, K. (2016). Jellyfish jelly press and jelly perception. Journal of Coastal Conservation, 20 (2), 117-125. https://doi.org/10.1007/s11852-016-0423-2

25. Yanes Luque, A. (2017) Desastres naturales en Canarias. La costa como espacio de riesgo en Tenerife. Sémata, Ciencias Sociais e Humanidades, 2017, vol. 29: 67-89. 